\title{
Nasal Carriage Rate, Antimicrobial Susceptibility Pattern, and Associated Factors of Staphylococcus aureus with Special Emphasis on MRSA among Urban and Rural Elementary School Children in Gondar, Northwest Ethiopia: A Comparative Cross-Sectional Study
}

\author{
Abiye Tigabu $\left(\mathbb{D},{ }^{1}\right.$ Moges Tiruneh, ${ }^{1}$ and Feleke Mekonnen ${ }^{(\mathbb{D}}{ }^{2}$ \\ ${ }^{1}$ Department of Medical Microbiology, School of Biomedical and Laboratory Sciences, University of Gondar, Gondar, Ethiopia \\ ${ }^{2}$ Department of Medical Laboratory Sciences, School of Health Sciences, College of Medicine and Health Sciences, \\ Bahir Dar University, Bahir Dar, Ethiopia \\ Correspondence should be addressed to Abiye Tigabu; abty12@gmail.com
}

Received 19 September 2018; Revised 13 November 2018; Accepted 25 November 2018; Published 11 December 2018

Academic Editor: William C. Cho

Copyright (c) 2018 Abiye Tigabu et al. This is an open access article distributed under the Creative Commons Attribution License, which permits unrestricted use, distribution, and reproduction in any medium, provided the original work is properly cited.

Introduction. Staphylococcus aureus is a Gram-positive, catalase-positive, and coagulase-positive bacterial species commonly found on the skin and in the nose of most healthy individuals. The anterior nares of nose are the most frequent carriage sites for $S$. aureus in both adults and children. Methicillin resistance among S. aureus isolates has steadily increased worldwide. Objective. The main objective of this study was to determine nasal carriage rate, antimicrobial susceptibility pattern, and associated risk factors of Staphylococcus aureus with special emphasis on MRSA among urban and rural elementary school children in Gondar, Northwest Ethiopia. Method. A community based comparative cross-sectional study was conducted on 622 urban and rural elementary school children in Gondar from January $1^{\text {st }}$ to March $30^{\text {th }}, 2018$. Data was collected using a questionnaire and nasal swab samples were collected by sterile cotton tip swab moistened with sterile normal saline. Collected samples were inoculated on mannitol salt agar and incubated aerobically at $37^{\circ} \mathrm{C}$ for $24 \mathrm{hrs}$. S. aureus was confirmed by observing colony characteristics and biochemical tests. MRSA was detected using cefoxitin disc by Modified Kirby-Bauer disk diffusion technique. Finally data was entered, cleared, and checked using Epi-info version 7 and exported to SPSS version 20 for analysis. Odds ratio and logistic regression were used for statistical association. P-value $\leq 0.05$ at $95 \%$ CI was considered for statistical association. Result. Of the 622 school children, the overall prevalence of $S$. aureus was 143/622 (23\%). Of them, 14/143 (9.79\%) were MRSA. The carriage rate in urban schools was $83 / 622$ (13.3\%) whereas it was 60/622 (9.6\%) in rural schools. The prevalence of MRSA among urban schools, 9.1\%, was higher than their urban counterparts, $0.7 \%$. Gentamycin, clindamycin, and ciprofloxacin were the most effective whereas penicillin and tetracycline were resistant. Children's fathers' educational status and number of children in class room were significantly associated with $S$. aureus but only living in urban of children significantly associated with MRSA. Conclusion. This study showed high prevalence of S. aureus and MRSA, 143/622 (23\%) and 14/143 (9.79\%), respectively. So, decolonization of nasal carriers of MRSA and reducing the number of students per classroom should be addressed. Moreover, regular large scale survey should be conducted to assess the burden and intervene accordingly.

\section{Introduction}

Staphylococcus aureus (S. aureus) is a Gram-positive, catalasepositive, and coagulase-positive bacteria commonly found mainly on the skin and nasal mucosa of most healthy individuals [1]. It is a frequent cause of clinically important infections ranging in severity from superficial infections to severe invasive diseases [2]. Approximately $20 \%$ of individuals are persistently nasal carriers of S. aureus and the rest $30 \%$ are intermittently colonized [3]. The anterior nares of nose 
are the primary reservoir for replication and spread to other body sites $[4,5]$.

Staphylococcus aureus exhibits increasing virulence and resistance to various antibiotics, complicating prevention, and treatment of infections [6]. Virulence factors are tightly regulated and act to degrade host cells, tissues, change the immune response, and enable for the dissemination inside and outside the host cell [7]. Overuse and misuse of antibiotics led to the emergence of bacterial antibiotic resistance [8]. Methicillin-resistant S. aureus (MRSA) carriage in healthy children is a major asymptomatic reservoir with an ability to quickly spread of MRSA within the community $[9,10]$.

MRSA is resistant to a large group of antibiotics called the beta lactams. Methicillin is a $\beta$-lactam antibiotic produced to treat penicillin resistant $S$. aureus. Methicillin-resistant $S$. aureus is a pathogenic strain responsible for difficult to treat infections in human [11]. MRSA resistance to antibiotics encoded by the mobile genetic element Staphylococcal chromosomal cassette (SCC) which carry the mecA gene and these elements vary in size and genetic content. The mecA gene encodes an altered penicillin binding protein (PBP2a) which permits the bacteria $S$. aureus to grow in the presence of methicillin and other $\beta$-lactam antibiotics $[12,13]$. PBP2a is located in the bacterial cell wall and has a low binding affinity for $\beta$-lactam antibiotics [14].

In Ethiopia, no population based study had been carried out on nasal carriage rate, antibiotic susceptibility pattern, and associated risk factors of $S$. aureus and MRSA among school children particularly in Gondar, Northwest Ethiopia. Thus, this study is intended to assess and fill the information gap of the current nasal carriage rate, antibiotic susceptibility pattern, and associated risk factors of $S$. aureus and MRSA among elementary school children in Gondar town. Also to indicate the prevention and control measures in the general community, it will also be used as preliminary information for future studies.

\section{Materials and Methods}

2.1. Study Area. The study was conducted in five governmental urban elementary schools in Gondar town and five governmental rural elementary schools surrounding Gondar town; Gondar town is the capital of North Gondar administrative zone, in Amhara region, Northwest Ethiopia.

2.2. Study Design and Periods. A community-based comparative cross-sectional study was conducted to determine nasal carriage rate, antimicrobial susceptibility pattern, and associated factors of Staphylococcus aureus with special emphasis on MRSA among elementary school children from January $1^{\text {st }}$ to May $30^{\text {th }}, 2018$.

2.3. Study Population. School children from recruited schools who gave sociodemographic information and nasal swab samples were included whereas children who were unable to give sociodemographic information, nasal swab specimen, and those who were on antibiotic therapy at the time of data collection were excluded

\subsection{Inclusion and Exclusion Criteria}

2.4.1. Inclusion Criteria. All randomly selected school children from recruited schools who have agreed to give sociodemographic information and nasal swab samples were included.

2.4.2. Exclusion Criteria. Children who were unable to give sociodemographic information and nasal swab specimen and those who were involuntary to participate in the study due to different reasons and children who were on antibiotic therapy at the time of data collection were also excluded.

2.5. Sample Size Determination and Sampling Technique. Single population proportion formula was used to determine the sample size and the calculated sample size was 258. However, adding 20\% nonresponse rate and a design effect of two, the final calculated sample size was 622. A multistage sampling technique was used to select schools by using simple random sampling technique and stratifying the schools to grades and sections. The number of study participants were allocated proportionally to each schools and grades based on the school sampling frame and the study subjects were selected by simple random sampling technique (lottery method).

2.6. Sociodemographic Data and Nasal Swab Specimen Collection. A pretested questionnaire based on postulated or known risk factors were developed and modified to explore the objectives of the study. Then sociodemographic characteristics and other relevant information were collected. Nasal swab specimen were collected by using sterile cotton tip swabs prewetted with sterile saline for each anterior nares by inserting the swab and gently rotating four to five times both in clockwise and in anticlockwise direction from each study participants. The nasal swabs were collected and inoculated immediately in a properly labeled sterile Tryptone Soya Broth (TSY) (Oxoid Ltd. England) and transported by using vaccine carrier which has ice box to maintain the temperature at 2$8^{\circ} \mathrm{C}$ until it reaches the laboratory.

2.7. Laboratory Inoculation and Identification. Each nasal sample was inoculated onto mannitol salt agar (Oxoid Ltd. England) and the plate was incubated aerobically at $37^{\circ} \mathrm{C}$ for $24 \mathrm{hrs}$. The sample that was positive for mannitol fermentation and golden yellow colonies on mannitol salt agar was further inoculated on blood agar (Oxoid Ltd. England) plate and incubated at $37^{\circ} \mathrm{C}$ for $24 \mathrm{hrs}$. The isolates obtained were identified using standard microbiological methods including colony morphology, Gram's stain reaction, and biochemical tests such as catalase and coagulase. Finally isolates that were golden yellow colony on mannitol salt agar and blood agar pate, Gram-positive cocci in clusters, catalase, and coagulase positive were confirmed as $S$. aureus.

2.8. Antimicrobial Susceptibility Testing. A suspension of pure colony from each confirmed culture isolate was done in sterile normal saline and incubated at $37^{\circ} \mathrm{C}$ for at least 15 minutes. The suspension was adjusted at $0.5 \%$ MacFarland standard. Then Modified Kirby-Bauer disk diffusion technique was 
implemented for antibiotic susceptibility pattern using different antibiotics such as penicillin (10 $\mu \mathrm{g})$, erythromycin $(15 \mu \mathrm{g})$, clindamycin $(2 \mu \mathrm{g})$, gentamicin $(10 \mu \mathrm{g})$, cotrimoxazole $(1.25 / 23.75 \mu \mathrm{g})$, cefoxitin $(30 \mu \mathrm{g})$, ciprofloxacin $(30 \mu \mathrm{g})$, and tetracycline $(30 \mu \mathrm{g})$. Moreover, inducible clindamycin resistance was tested using D-test by putting erythromycin and clindamycin discs at a distance of $15 \mathrm{~mm}$ from each other on Muller Hinton agar plate (Oxoid Ltd. England). Then after incubation at $37^{\circ} \mathrm{C}$ for $24 \mathrm{hrs}$, flattening of zone (D-shaped) around clindamycin in the area between erythromycin and clindamycin discs was observed and interpreted as inducible clindamycin resistant.

All Staphylococcus aureus isolates were tested for methicillin susceptibility patterns by using Modified Kirby-Bauer disc diffusion technique. Cefoxitin $(30 \mu \mathrm{g})$ (Oxoid Ltd. England) discs were placed in the plates and then incubated aerobically at $35^{\circ} \mathrm{C}$ for $24 \mathrm{hrs}$. Zone inhibition in millimeters was measured with a ruler. Isolates were classified as resistant, intermediate, and sensitive based on CLSI 2017 interpretation [15]. Finally those which were resistant to cefoxitin $(\leq 21 \mathrm{~mm})$ were confirmed as MRSA. Known strains of S. aureus (ATCC 25923) was inoculated to cheek the performance of culture media as a positive control for catalase, coagulase, and antibiotic susceptibility testing. And Escherichia coli (ATCC 25922) strain was used as a negative control. Gram stain reagents were also cheeked by preparing smears from known S. aureus (ATCC 25923) strain and observing them under the microscope.

2.9. Data Entry and Analysis. Data was entered using EPIInfo version 7 and its completeness and clearance was checked and then transferred to SPSS version 20 for analysis. The characteristics of the study population were summarized using frequencies, mean, and standard deviation. Binary logistic regression was done to determine the association of variables with $S$. aureus and MRSA. Crude odds ratio was calculated. Moreover, adjusted odds ratio was computed using multivariate logistic regression for variables with $\mathrm{p}$ value $\leq 0.2$. P-value $\leq 0.05$ at $95 \% \mathrm{CI}$ was considered as statistically significant.

\section{Result}

3.1. Sociodemographic Characteristics. A total of 622 urban and rural elementary school children were included in the study; of these, $317 / 622(51 \%)$ were males. The ages of the study participants ranged from 6 to 25 years with a mean age of 11.9 years (SD+2.9). Most of the study participants, 345/622 (55.5\%), belonged to the age group of 11-15 years of age and $345 / 622(55.5 \%)$ were from urban elementary schools while the rest, $277 / 622$ (44.5\%), were from rural schools. Among the study participants, $321 / 622(51.6 \%)$ had a family size of greater than five members and 271/622 (43.6\%) had mothers who were unable to read and write (Table 1).

Majority of the study participants, 545/622(87.6\%), had no history of chronic disease, but from the total of participants, almost half, 299/622(48.1\%), of the study participants had history of visit to hospitals/clinics. On top of that, 522/622(83.9\%) had not history of hospitalization; 583/622
(93.7\%) had not history of surgery; 551/622 (88.6\%) had not history of contact with health care worker; 529/622(85\%) had not history of antibiotic usage in the past 4 weeks; and the rest, 531/622 (85.4\%), had not history of respiratory infection (Table 1).

Majority, 295/622 (47.4\%), of the study participant's family's average monthly income was less than 18 dollar followed by $197 / 622(31.7 \%)$, greater than 36 dollar, and 130/622 (20.9\%), 18-36 dollar incomers. Majority of the fathers of the study participants, $211 / 622(33.9 \%)$, were unable to read and write followed by 146/622 (23.5\%), primary school; 103/622 (16.6\%), secondary school; 97/622 (15.6\%), informal education; and 65/622 (10.5\%), above grade 12 attenders (Table 1).

3.2. Prevalence of Staphylococcus aureus and MRSA. Out of 622 study participants, the overall prevalence of $S$. aureus was $143 / 622$ (23\%); of these 14/143 (9.79\%) were MRSA strains. From the total of 143 isolates, 79/622(12.7\%) were isolated from male participants, of which 7/79 (8.86\%) were MRSA. And 64/622 (10.3\%) isolates were from females, of which $7 / 64(10.94 \%)$ were MRSA isolates. Highest nasal carriage rate of $S$. aureus, $26 / 622(4.2 \%)$, was shown among grade four students, from which MRSA stains were 2/26 (7.7\%) (Table 2).

In urban elementary schools, the $S$. aureus carriage rate was $83 / 622(13.3 \%)$ whereas in the rural schools, it was $60 / 622$ (9.6\%). The frequency of MRSA among S. aureus positive children in urban and rural school children was 13/143 (9.1\%) and $1 / 143(0.7 \%)$, respectively. The overall prevalence of inducible clindamycin resistant $S$. aureus in this study was $12 / 622(1.93 \%)$.

The frequency of $S$. aureus nasal carriage in males was $45 / 622(7.23 \%)$ in urban as compared to $34 / 622(5.5 \%)$ in rural schools and that of females was $38 / 622(6.1 \%)$ in urban as compared to $26 / 622(4.2 \%)$ in rural schools. The prevalence of MRSA nasal carriage in males was 6/143 (4.2\%) in urban as compared to $1 / 143(0.7 \%)$ in rural schools while that in females was $7 / 143(4.9 \%)$ in urban as compared to $0 / 143(0 \%)$ in rural schools. The carriage rate of $S$. aureus reached its peak at the age of $11,20 / 622(3.2 \%)$. High prevalence of $S$. aureus nasal carriage, 81/622 (13\%), was observed under age group of 11-15 years of age. But high carriage rate of MRSA, 8/143 (5.6\%), was observed under age group of 6-10 years of age (Table 2).

Among urban elementary school children, high rate of S. aureus isolates was observed in Meseret, 22/343 (6.4\%), followed by Felege Abyot, 21/343 (6.1\%); Atsebekafa, 16/343 (4.7\%); Chechela, 15/343 (4.4\%); and Hibret, 11/343 (3.2\%), while high rate of MRSA isolation was observed in Chechela, 7/85 (8.2\%), followed by Meseret, 3/85 (3.5\%); Atsebekafa, 2/85 (2.4\%); and Felege Abyot, 1/85 (1.2\%) (Figure 1). Among rural elementary school children, high rate of $S$. aureus was observed in Kelel Rufael, 20/279 (7.2\%), followed by Maryam Deber, 17/279 (6.1\%); Arbaba, 12/279 (4.3\%); Walaji, 8/279 (2.9\%); and Azezo Tekelhaymanot, 1/279 (0.4\%). But only one MRSA strain was found in Kelel Rufael, 1/58 (1.7\%), of rural elementary school (Figure 2). 
TABLE 1: Sociodemographic characteristics of study participants among elementary school children in Gondar, Northwest Ethiopia, 2018.

\begin{tabular}{|c|c|c|c|}
\hline Characteristics & & $\begin{array}{c}\text { Frequency } \\
(\mathrm{n}=622)\end{array}$ & Percentage (\%) \\
\hline \multirow{2}{*}{ Residence } & Urban & 345 & 55.5 \\
\hline & Rural & 277 & 44.5 \\
\hline \multirow{2}{*}{ Sex } & Male & 317 & 51 \\
\hline & Female & 305 & 49 \\
\hline \multirow{3}{*}{ Age in years } & $6-10$ years & 221 & 35.5 \\
\hline & $10-15$ years & 345 & 55.5 \\
\hline & $>15$ years & 56 & 9.0 \\
\hline \multirow{2}{*}{ Educational status } & Grade 1-4 & 308 & 49.5 \\
\hline & Grade 5-8 & 314 & 50.5 \\
\hline \multirow{3}{*}{ Family's monthly income } & Less than 500 birr & 295 & 47.4 \\
\hline & 500-1000 birr & 130 & 20.9 \\
\hline & Greater than 1000 birr & 197 & 31.7 \\
\hline \multirow{2}{*}{ Family size category } & $2-5$ & 301 & 48.4 \\
\hline & Greater than 5 & 321 & 51.6 \\
\hline \multirow{3}{*}{$\begin{array}{l}\text { Number of students in classroom } \\
\text { category }\end{array}$} & $21-40$ & 75 & 12.1 \\
\hline & $41-60$ & 486 & 78.1 \\
\hline & $>60$ & 61 & 9.8 \\
\hline \multirow{2}{*}{ History of chronic disease } & Yes & 77 & 12.4 \\
\hline & No & 545 & 87.6 \\
\hline \multirow{2}{*}{ History of hospitalization } & Yes & 100 & 16.1 \\
\hline & No & 522 & 83.9 \\
\hline \multirow{2}{*}{ History of surgery } & Yes & 39 & 6.3 \\
\hline & No & 583 & 93.7 \\
\hline \multirow{2}{*}{ History of visit hospitals/clinics } & Yes & 299 & 48.1 \\
\hline & No & 323 & 51.9 \\
\hline \multirow{2}{*}{$\begin{array}{l}\text { History of contact with health care } \\
\text { worker }\end{array}$} & Yes & 71 & 11.4 \\
\hline & No & 551 & 88.6 \\
\hline \multirow{2}{*}{$\begin{array}{l}\text { History of antibiotic usage in the } \\
\text { past } 4 \text { weeks }\end{array}$} & Yes & 93 & 15.0 \\
\hline & No & 529 & 85.0 \\
\hline \multirow{2}{*}{ History of respiratory infection } & Yes & 91 & 14.6 \\
\hline & No & 531 & 85.4 \\
\hline \multirow{5}{*}{ Mothers' educational status } & Unable to read \& write & 271 & 43.6 \\
\hline & Informal education & 68 & 10.9 \\
\hline & Primary school & 153 & 24.6 \\
\hline & Secondary school & 81 & 13.0 \\
\hline & Above grade 12 & 49 & 7.9 \\
\hline \multirow{5}{*}{ Fathers' educational status } & Unable to read \& write & 211 & 33.9 \\
\hline & Informal education & 97 & 15.6 \\
\hline & Primary school & 146 & 23.5 \\
\hline & Secondary school & 103 & 16.6 \\
\hline & Above grade 12 & 65 & 10.5 \\
\hline
\end{tabular}

3.3. Antimicrobial Susceptibility Patterns. The antimicrobial susceptibility pattern result showed that, among 143 S. aureus isolates, $129 / 143(90.2 \%)$ were MSSA and the rest, 14/143 (9.79\%), were MRSA. Majority of the isolates of S. aureus were sensitive for gentamycin (98.6\%), clindamycin $(93.7 \%)$, ciprofloxacin (93\%), cefoxitin (90.2\%), cotrimoxazole (84\%), and erythromycin (55\%). Some isolates of S. aureus, 44/143 (30.8\%), showed multidrug resistance patterns. However, majority of the isolates were resistant to penicillin $(99.3 \%)$ and tetracycline (71.33\%) (Table 3 ). 
TABLE 2: Prevalence of Staphylococcus aureus with special emphasis on MRSA among study participants in urban and rural elementary school children in Gondar, Northwest Ethiopia, 2018.

\begin{tabular}{|c|c|c|c|c|c|c|c|c|}
\hline \multirow{3}{*}{ Characteristics } & & \multicolumn{7}{|c|}{ Schools } \\
\hline & & \multirow[t]{2}{*}{ No. (\%) } & \multirow{2}{*}{\multicolumn{2}{|c|}{$\begin{array}{l}\text { Urban } \\
\text { + Ve for } \\
\text { MRSA (\%) }\end{array}$}} & \multirow[b]{2}{*}{$\begin{array}{c}\text {-ve for S.A } \\
(\%)\end{array}$} & \multirow[b]{2}{*}{$\begin{array}{c}\text { +ve for S.A } \\
(\%)\end{array}$} & \multirow{2}{*}{$\begin{array}{c}\text { Rural } \\
+ \text { Ve for } \\
\text { MRSA (\%) }\end{array}$} & \multirow[b]{2}{*}{$\begin{array}{c}\text {-ve for S.A } \\
(\%)\end{array}$} \\
\hline & & & & & & & & \\
\hline \multirow{4}{*}{ Age } & $6-10$ years & $221(35.53)$ & $30(22.73)$ & $7(23.33)$ & $102(77.27)$ & $18(20.23)$ & $1(5.56)$ & $71(79.78)$ \\
\hline & $11-15$ years & $345(55.47)$ & $50(26.32)$ & $4(8)$ & $140(73.68)$ & $31(20)$ & $0(0)$ & $124(80)$ \\
\hline & $>15$ years & $56(9.0)$ & $3(13.04)$ & $2(8.70)$ & $20(86.96)$ & $11(33.33)$ & $0(0)$ & $22(66.67)$ \\
\hline & Total & $622(100)$ & $83(24.06)$ & $13(15.66)$ & $262(75.94)$ & $60(21.66)$ & $1(1.67)$ & $217(78.34)$ \\
\hline \multirow{3}{*}{ Sex } & Male & $317(50.97)$ & $45(25.57)$ & $6(13.33)$ & $128(72.73)$ & $34(23.61)$ & $1(2.94)$ & $110(76.39)$ \\
\hline & Female & $305(49.04)$ & $38(22.09)$ & $7(18.42)$ & $134(77.91)$ & $26(19.55)$ & $0(0)$ & $107(80.45)$ \\
\hline & Total & $622(100)$ & $83(24.06)$ & $13(15.66)$ & $262(75.94)$ & $60(21.66)$ & $1(1.67)$ & $217(78.34)$ \\
\hline \multirow{3}{*}{ Family size } & $2-5$ & $301(48.39)$ & $44(22.45)$ & 8 (18.18) & $152(77.55)$ & $18(17.14)$ & $0(0)$ & $87(82.86)$ \\
\hline & $>5$ & $321(51.61)$ & $39(26.17)$ & $5(12.82)$ & $110(73.83)$ & $42(24.42)$ & $1(2.38)$ & $130(75.58)$ \\
\hline & Total & $622(100)$ & $83(24.06)$ & $13(15.66)$ & $262(75.94)$ & $60(21.66)$ & $1(1.67)$ & $217(78.34)$ \\
\hline Residence & & $622(100)$ & $83(24.06)$ & $13(15.66)$ & $262(75.94)$ & $60(21.66)$ & $1(2.67)$ & $217(78.34)$ \\
\hline \multirow{9}{*}{ Educational level } & Grade 1 & 74 (11.9) & $9(23.68)$ & 1(11.11) & $29(76.32)$ & $8(22.22)$ & $0(0)$ & $28(77.78)$ \\
\hline & Grade 2 & $75(12.06)$ & $8(18.18)$ & $1(12.5)$ & $36(81.81)$ & $8(25.81)$ & $1(12.5)$ & $23(74.19)$ \\
\hline & Grade 3 & $79(12.7)$ & $7(18.42)$ & $2(28.57)$ & $31(81.58)$ & $5(122)$ & $0(0)$ & $36(87.81)$ \\
\hline & Grade 4 & $78(12.54)$ & $16(37.21)$ & $2(12.5)$ & $27(62.79)$ & $10(28.57)$ & $0(0)$ & $25(71.43)$ \\
\hline & Grade 5 & 87 (13.99) & $11(21.15)$ & $3(27.27)$ & $41(78.85)$ & $6(17.14)$ & $0(0)$ & $29(82.86)$ \\
\hline & Grade 6 & $81(13.02)$ & $11(26.19)$ & $1(9.09)$ & $31(73.81)$ & $6(15.39)$ & $0(0)$ & $33(84.62)$ \\
\hline & Grade 7 & 77 (12.38) & $11(26.19)$ & $0(0)$ & $31(73.81)$ & $10(28.57)$ & $0(0)$ & $25(71.43)$ \\
\hline & Grade 8 & $71(11.42)$ & $10(21.74)$ & $3(30)$ & $36(78.26)$ & $7(28)$ & $0(0)$ & $18(72)$ \\
\hline & Total & $622(100)$ & $83(24.06)$ & $13(15.66)$ & $262(75.94)$ & $60(21.66)$ & $1(1.67)$ & $217(78.34)$ \\
\hline
\end{tabular}

TABLE 3: Antibiotic susceptibility patterns of Staphylococcus aureus isolates in Gondar town, Northwest Ethiopia, 2018.

\begin{tabular}{|c|c|c|c|c|c|c|c|c|c|c|c|c|}
\hline \multirow{4}{*}{ Antibiotics } & \multicolumn{12}{|c|}{ Schools } \\
\hline & \multirow{2}{*}{\multicolumn{3}{|c|}{$\begin{array}{l}\text { Urban (83) } \\
\text { MSSA (70) }\end{array}$}} & \multirow{2}{*}{\multicolumn{3}{|c|}{$\begin{array}{l}\text { Rural (60) } \\
\text { MSSA (59) }\end{array}$}} & \multirow{2}{*}{\multicolumn{3}{|c|}{$\begin{array}{c}\text { Urban } \\
\text { MRSA (13) }\end{array}$}} & \multirow{2}{*}{\multicolumn{3}{|c|}{$\begin{array}{c}\text { Rural } \\
\text { MRSA (1) }\end{array}$}} \\
\hline & & & & & & & & & & & & \\
\hline & S (\%) & I (\%) & R (\%) & S (\%) & I (\%) & R (\%) & S (\%) & I (\%) & R (\%) & S (\%) & I (\%) & R (\%) \\
\hline $\begin{array}{l}\text { Penicillin (10 } \\
\mu \mathrm{g})\end{array}$ & $0(0)$ & $0(0)$ & 70 (100) & $1(1.7)$ & $0(0)$ & $58(98.31)$ & $0(0)$ & $0(0)$ & $13(100)$ & $0(0)$ & $0(0)$ & $1(100)$ \\
\hline $\begin{array}{l}\text { Erythromycin } \\
(15 \mu \mathrm{g})\end{array}$ & $42(60)$ & $21(30)$ & $7(10)$ & $32(54.4)$ & $9(15.3)$ & $18(30.5)$ & $3(23.08)$ & $2(15.39)$ & $8(61.54)$ & $1(100)$ & $0(0)$ & $0(0)$ \\
\hline $\begin{array}{l}\text { Clindamycin } \\
(2 \mu \mathrm{g})\end{array}$ & 65 (92.9) & $2(2.88)$ & $3(4.29)$ & $59(100)$ & $0(0)$ & $0(0)$ & $9(69.23)$ & $0(0)$ & $4(30.77)$ & $1(100)$ & $0(0)$ & $0(0)$ \\
\hline $\begin{array}{l}\text { Gentamicin } \\
(10 \mu \mathrm{g})\end{array}$ & 69 (98.57) & $0(0)$ & $1(1.43)$ & $59(100)$ & $0(0)$ & $0(0)$ & $12(92.31)$ & $1(7.69)$ & $0(0 \%)$ & $1(100)$ & $0(0)$ & $0(0)$ \\
\hline $\begin{array}{l}\text { TMP/SMX } \\
(1.25 / 23.75 \mu \mathrm{g})\end{array}$ & $59(84.29)$ & $6(8.57)$ & $5(7.14)$ & $51(86.44)$ & $2(3.39)$ & $6(10.17)$ & $9(69.23)$ & $1(7.69)$ & $3(23.08)$ & $1(100)$ & $0(0)$ & $0(0)$ \\
\hline $\begin{array}{l}\text { Cefoxitin (30 } \\
\mu \mathrm{g})\end{array}$ & 70 (100) & $0(0)$ & $0(0)$ & $59(100)$ & $0(0)$ & $0(0)$ & $0(0)$ & $0(0)$ & $13(100)$ & $0(0)$ & $0(0)$ & $1(100)$ \\
\hline $\begin{array}{l}\text { Ciprofloxacin } \\
(30 \mu \mathrm{g})\end{array}$ & $63(90)$ & $6(8.57)$ & $1(1.43)$ & $59(100)$ & $0(0)$ & $0(0)$ & $10(76.92)$ & $1(7.69)$ & $2(15.38)$ & $1(100)$ & $0(0)$ & $0(0)$ \\
\hline $\begin{array}{l}\text { Tetracycline } \\
(30 \mu \mathrm{g})\end{array}$ & 11 (15.71) & $14(20)$ & $45(64.29)$ & $7(11.86)$ & $4(6.78)$ & $48(81.67)$ & $1(7.36)$ & $4(30.77)$ & $8(61.54)$ & $0(0)$ & $0(0)$ & $1(100)$ \\
\hline
\end{tabular}

$\mathrm{S}=$ susceptible, $\mathrm{I}=$ intermediate, and $\mathrm{R}=$ resistance. 


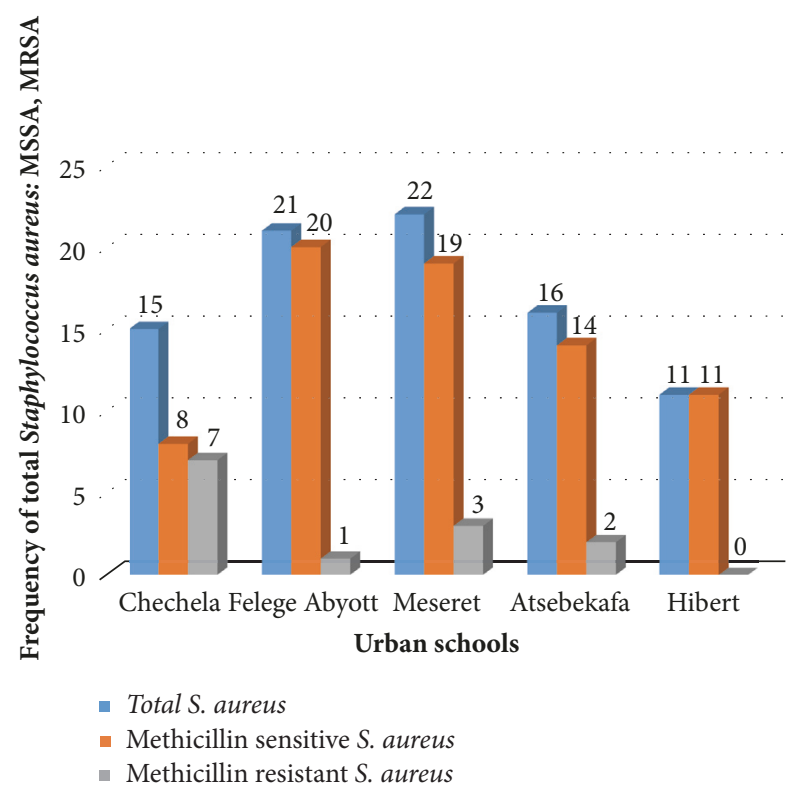

FIGURE 1: Frequency of total Staphylococcus aureus, MSSA, and MRSA in five urban elementary school children, Gondar town, Northwest Ethiopia, 2018.

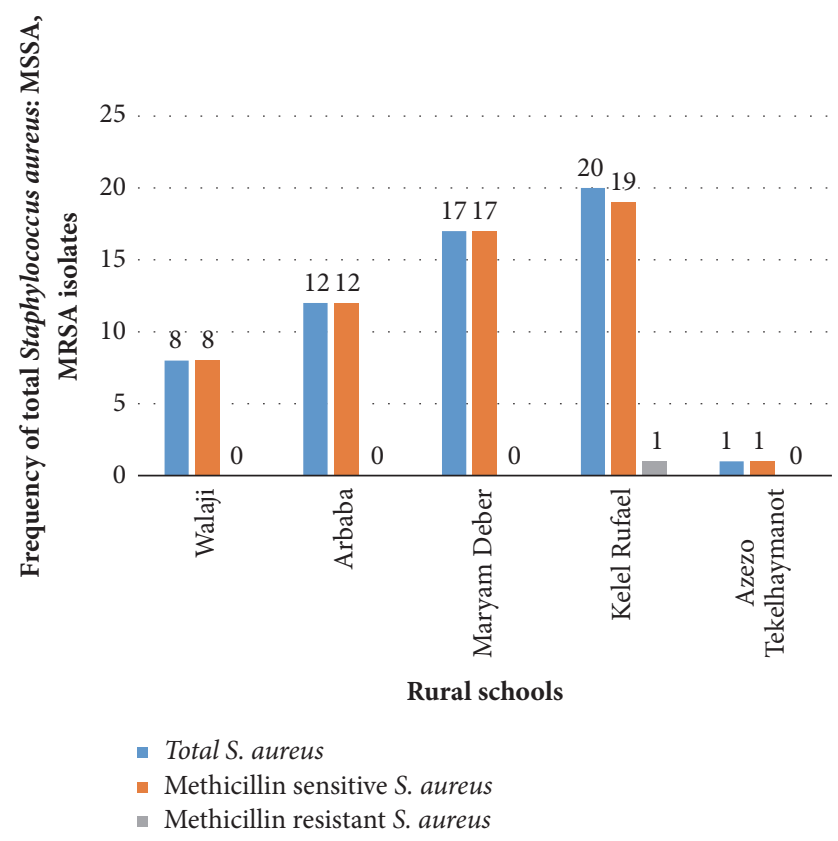

FIgURE 2: Frequency of total Staphylococcus aureus, MSSA, and MRSA in five rural elementary school children, surrounding Gondar town, Northwest Ethiopia, 2018.

3.4. Risk Factors. Among 622 elementary school children included in the study, father's educational status $(\mathrm{P}=0.039$; $\mathrm{AOR}=1.98 ; \mathrm{CI}=1.063-3.685)$ and number of students in classroom belonged to 41-60 $(\mathrm{P}=0.031$; $\mathrm{AOR}=0.41$; $\mathrm{CI}=$ $0.18-0.92)$ and 21-40 category $(\mathrm{P}=0.046$; $\mathrm{AOR}=0.38 ; \mathrm{CI}=$ $0.15-0.98)$ were significant risk factors for nasal colonization of $S$. aureus. However, majority of the study variables were not risk factors for nasal colonization of S. aureus (Table 4). Among the $143 \mathrm{~S}$. aureus nasal carriers of children in the study, living in urban of children $(\mathrm{P}=0.036$; $\mathrm{AOR}=0.107$; $\mathrm{CI}$ $=0.013-0.866)$ was significantly associated with MRSA nasal colonization. However, majority of the study variables were not risk factors for MRSA nasal colonization (Table 5).

\section{Discussion}

According to studies which were conducted on nasal colonization of Staphylococcus aureus, approximately 20-30\% of healthy persons are persistent nasal carriers with high colonization rates among children $[3,9]$. There was an important association between nasal carriage rates of $S$. aureus and development of subsequent infections [6]. MRSA had emerged in various geographically distinct communities outside of health care settings without known health care associated risk factors [12].

In this study, $S$. aureus nasal carriage rate among school children was $23 \%$. This finding of $S$. aureus nasal carriage was in line with the reports in Ghana (22.6\%) [16]. However, higher prevalence of $S$. aureus nasal carriage rate was reported in this study than Serbia (2.59\%), China (2.4\%), Iraq (17.75\%), Vietnam (10.4\%), and Nigeria (18.3\%) [2, 17-19]. On the other hand, this finding showed lower prevalence of $S$. aureus nasal carriage rate than the reports in Italy (39.2\%), India (25\%), Iran (28\%), Iraq (30\%), Nigeria (56.3\%), Jimma (47.34\%), and Bahir Dar (41\%) [5, 20-25]. This variation of nasal carriage rate of $S$. aureus from other studies might be due to difference in the characteristics of the study population, quality of sampling, culturing techniques, geographical distribution, and diagnostic techniques.

The nasal carriage rate of MRSA among school children was $9.79 \%$. This nasal carriage of MRSA was less than the WHO 2014 estimated range of MRSA for African region (12-80\%) [26]. This finding of MRSA nasal carriage was in line with the reports of Iraq (11.1\%) [23] and higher than the reports in Serbia (7.55\%), Ghana (1.6\%), Italy (1.54\%), India $(3.17 \%)$, and Jordan (7.1\%) [16, 17, 20, 21, 27]. However, this MRSA nasal carriage was lower than the reports in Iran (21.74\%), Nigeria (59.1\%), Iraq (13.3\%), Vietnam (12.3\%), Jimma (18.8\%), and Bahir Dar (13.8\%) [18, 19, 22, 24, 25, 28]. This variation might be due to the difference in the diagnostic techniques which was used to confirm/detect MRSA other than cefoxitin disc detection method.

In this study, among 143 children who had S. aureus, 79/143(55.2\%) were male which indicates higher proportion of nasal carriage rate of $S$. aureus among male students than females, 64/143 (44.8\%). This result is in agreement with previous studies which were conducted in Nigeria and Iraq $[1,8]$. This higher prevalence in males might be due to male students participated in sport activities more often than females which makes them more vulnerable to colonization. Nasal carriage of S. aureus and MRSA, 83/143 (58\%) and $13 / 83(15.66 \%)$, respectively, was higher in urban than rural residents, $60 / 143(42 \%)$ and $1 / 60(1.67 \%)$. This might be due to overcrowding and the presence of large number of governmental and nongovernmental health care facilities 


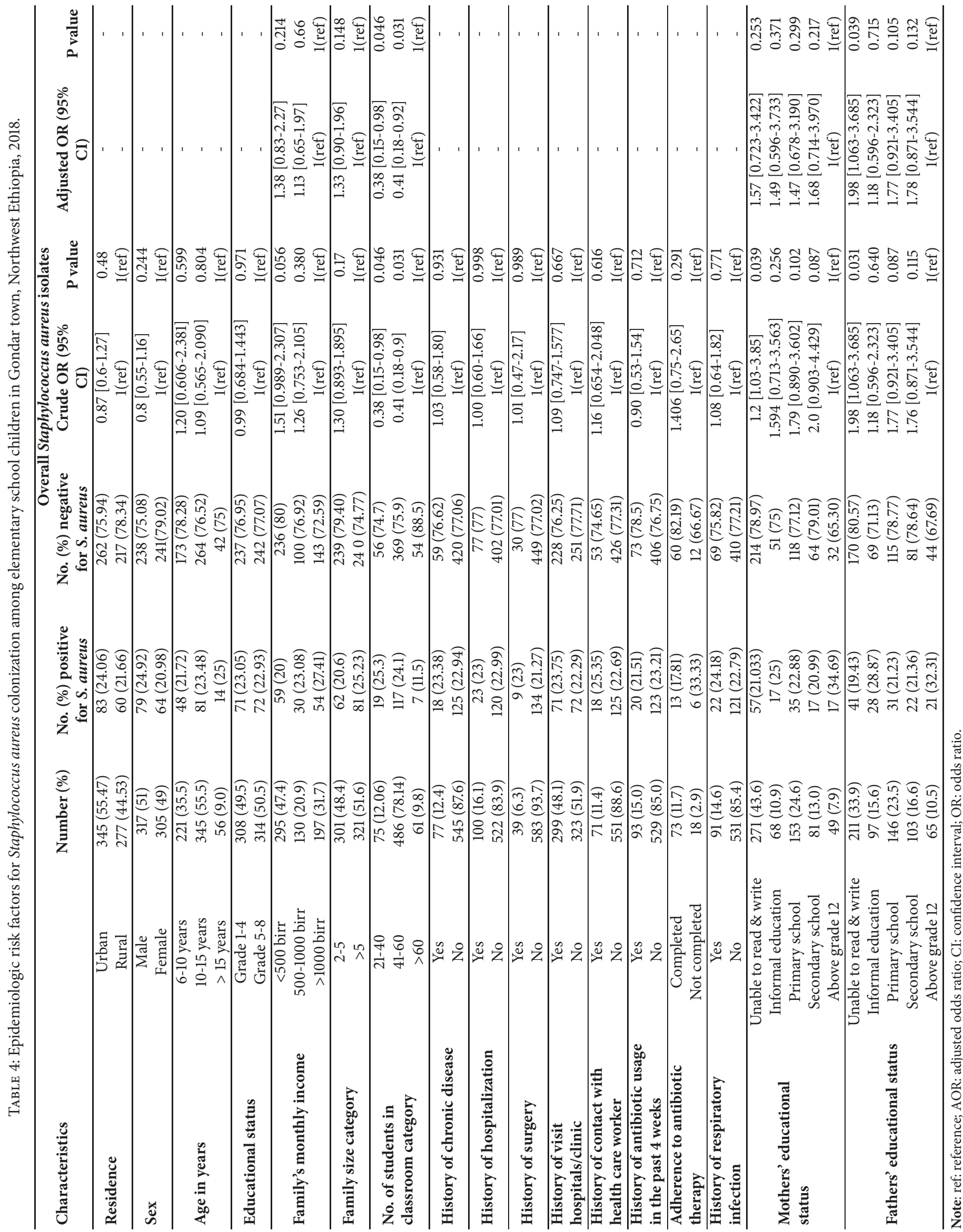




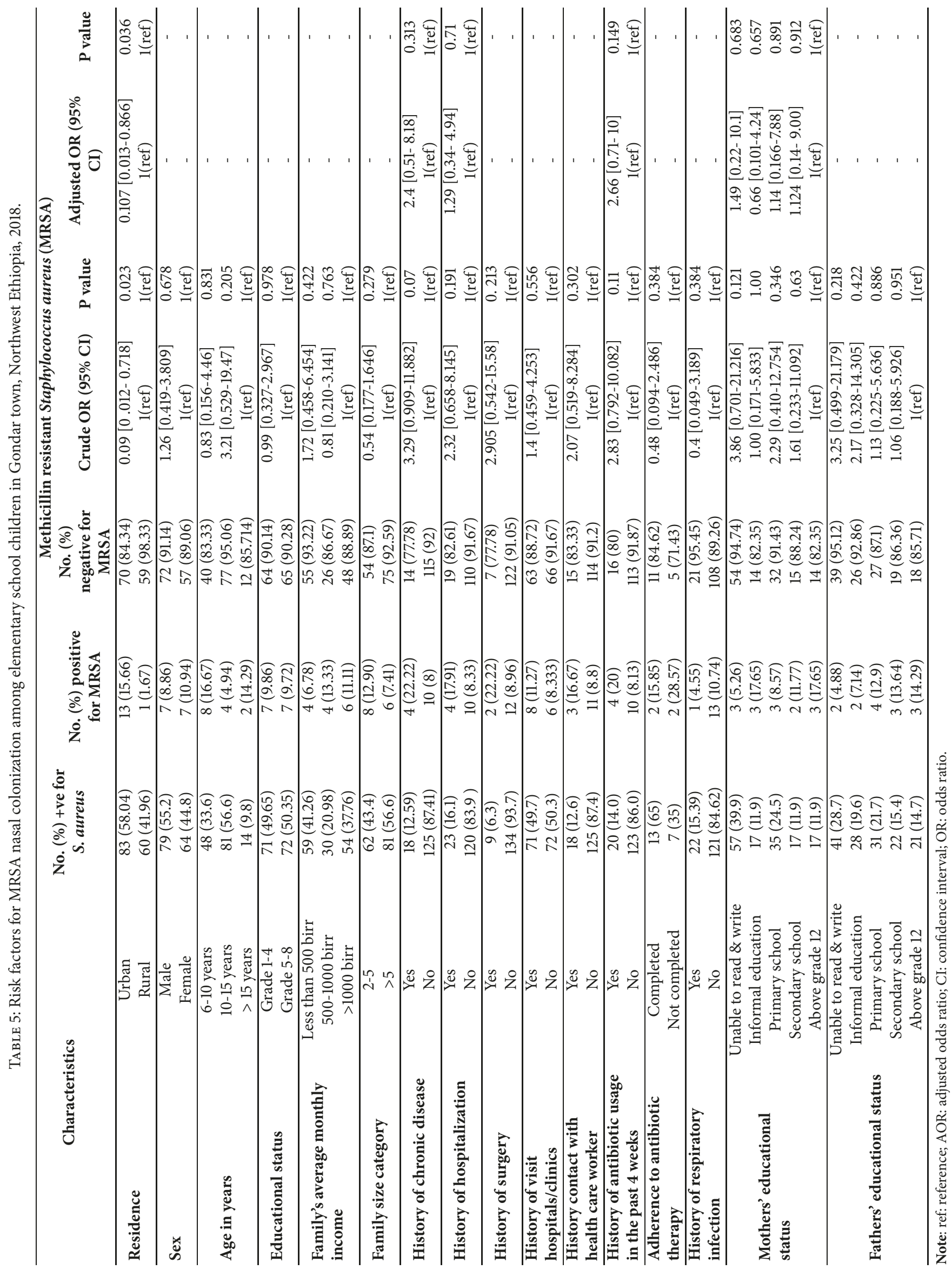


such as hospitals and health centers/clinics in the urban than rural community.

Regarding the antimicrobial susceptibility pattern result there were more than $99 \%$ and $70 \%$ resistance strains to penicillin and tetracycline, respectively. In this study antimicrobial susceptibility test showed that penicillin and tetracycline were the least effective agent with more than $70 \%$ bacterial resistance. This result of penicillin resistant was in line with various studies which was conducted on healthy children in China (87.5\%), Nigeria (100\%), Ghana (95\%), Jimma (100\%), and Bahir Dar (100\%) [2, 16, 19, 24, 25]. Majority of S. aureus isolates showed $99.3 \%$ resistance to penicillin. Similarly, MRSA isolates showed $100 \%$ resistance to penicillin and cefoxitin. This result was similar to a study conducted in Nigeria (100\%), Jimma (100\%), and Bahir Dar $(100 \%)[1,24,25]$.

Majority of the isolated $S$. aureus were sensitive for clindamycin (94\%), gentamycin (98.6\%), cefoxitin (90.2\%), cotrimoxazole $(84 \%)$, and ciprofloxacin $(93 \%)$. However, some of them, 32/143(22.4\%), were intermediate resistance for erythromycin. This finding was similar to several studies in Serbia, Jimma, Jordan, and Bahir Dar [17, 24, 25, 27]. Gentamycin was the most susceptible antibiotic (98.6\%) which was in agreement with a study in Nigeria (95\%) [1].

The majority of the isolated $S$. aureus strains were sensitive for tested antimicrobial agents. However, 44/143 $(30.8 \%)$ of isolates of $S$. aureus showed multidrug resistance patterns. The highest MDR pattern, 27/143 (18.9\%), was observed for penicillin, tetracycline, and erythromycin. 5/143 (3.5\%) of isolates were resistant for penicillin, cotrimoxazole, tetracycline, and erythromycin. One isolate was resistant for six antibiotics: penicillin, cotrimoxazole, tetracycline, erythromycin, clindamycin, and gentamycin. The differences in susceptibility pattern of the isolates might be due to frequent and irrational use of antibiotics, illegal drug healing in our setup, and differences in geographical area.

Among elementary school children, high rate of isolation of MRSA was reported in urban elementary schools. The high prevalence of MRSA in urban schools than rural might be due to reasons; for example, urban schools were more closer to health care facility; high antibiotic selective pressure in urban settings and overcrowding was more prominent in urban than rural schools.

Several studies showed that sociodemographic characteristics and risk factors contribute a lot to the nasal carriage of $S$. aureus and MRSA [5, 21, 22, 24, 25, 27, 28]. The result of this study showed children's father's educational status significantly associated with nasal carriage of $S$. aureus which was in contrast with a study in Nigeria [12]. The less the level of education among fathers of school children, the more likely for nasal carriage of $S$. aureus was observed. The possible reason might be that the less level of the fathers education, the less they care their children socioeconomically and hygienically.

Number of students in classroom was significant risk factors for nasal colonization of $S$. aureus. Majority of the students who had high nasal carriage of $S$. aureus belonged among children with 41-60 classmates in the class room which showed that the increase in the number of students per class room, the more likely the nasal carriage of $S$. aureus was observed in school children. This result was consistent with study conducted in Ethiopia, Jimma [24]. The possible reason might be due to the fact that high number of students in one class room makes them more frequent contact among each other, overcrowding, and greater sharing of nasal flora which causes the more spread of the bacteria.

Living in urban of children involved in this study was statistically significant risk factor for nasal colonization of MRSA. This study showed that being urban elementary school children had more likely hood for nasal carriage of MRSA than rural school children. The possible reason might be due to children living in the urban community which makes them contact with health care workers more frequently and more exposed to health care facilities and overcrowding in the urban area which increases nasal carriage of MRSA in urban schools.

\section{Limitation of the Study}

We did not perform vancomycin minimum inhibitory concentration due to resource constraints and advanced molecular techniques like PCR which may underestimate the true prevalence in the study population.

\section{Conclusion}

The prevalence of S. aureus and MRSA among primary school children was $23 \%$ and $9.79 \%$, respectively. Father's educational status and number of students in class room were independent risk factors for nasal colonization of $S$. aureus. Moreover, being urban school children's were at risk of MRSA nasal colonization. Therefore, health education, screening of target population, and decolonization of carriers are effective prevention strategies to control the spread and burden of drug resistant $S$. aureus and MRSA within elementary schools and community. Large community-based studies, molecular distinction between hospital acquired-MRSA and community acquired-MRSA, continuous surveillance, screening of target population, and decolonization of carriers should be conducted to decrease the spread and burden of drug resistant $S$. aureus and MRSA in the elementary schools and the community at large.

\section{Abbreviations}

ATCC: American Type of Culture Collection

CI: $\quad$ Confidence Interval

CLSI: Clinical and Laboratory Standards Institute

EPI-Info: Epidemiological Information

MRSA: Methicillin Resistance Staphylococcus aureus

MSSA: Methicillin Susceptible Staphylococcus aureus

AOR: $\quad$ Adjusted odds ratio

PBP2a: Penicillin binding protein

S.A: $\quad$ Staphylococcus aureus

S. aureus: Staphylococcus aureus

SCCmec: Staphylococcal Cassette Chromosome mec

SD: $\quad$ Standard Deviation

SPSS: $\quad$ Statistical Package for Social Sciences 
TMP/SMZ: Trimethoprim-sulfamethoxazole

TSY: $\quad$ Tryptone Soya Broth

WHO: World Health Organization.

\section{Data Availability}

All data generated or analyzed during this study are included in this article. Data that support the findings of this study are also available from the corresponding author upon reasonable request.

\section{Ethical Approval}

Ethical clearance was obtained from University of Gondar Ethical Review Committee. Written permission was obtained from Gondar Town Administration Health Office.

\section{Consent}

A written informed consent from parents and assent from children were obtained. Additionally confidentiality of information was assured.

\section{Conflicts of Interest}

The authors declare that they do not have conflicts of interest.

\section{Authors' Contributions}

Abiye Tigabu contributed to conception of research idea, study design, data collection, analysis and interpretation, manuscript writing, and review. Moges Tiruneh contributed to research idea, data collection, analysis, and interpretation. Feleke Mekonnen contributed to supervision, analysis, interpretation, thesis preparation, manuscript writing, and review. All authors read and approved the final manuscript.

\section{Acknowledgments}

We would like to thank all participants of this research, all the study participants, and directors of each elementary school for their active and voluntary participation and cooperation.

\section{References}

[1] M. Ugwu, N. Mokwe, P. Ejikeugwu et al., "Antibiogram of Staphylococcus aureus from healthy school pupils in Agulu, Southeastern Nigeria," International Journal of Research in Pharmacy and Biosciences, vol. 2, no. 4, p. 5, 2015.

[2] J. Deng, G. Xiao, Y. Zhu, W. Zhou, and C. Wan, "Staphylococcus aureus nasal carriage and its antibiotic resistance profiles in Tibetan school children in Southwest China," Hong Kong Journal of Pediatrics, vol. 19, pp. 75-78, 2014.

[3] C. Paulino, R. D. Garcia, and S. Ong, "Staphylococcus aureus nasal carriage rates among children between one-to-five years in Barangay Pio Del Pilar, Makati City," Pediatric Infectious Disease Society of the Philippines Journal, vol. 14, no. 1, pp. 24-33, 2013.
[4] M. B. Miller, D. J. Weber, J. S. Goodrich et al., "Prevalence and risk factor analysis for methicillin-resistant Staphylococcus aureus nasal colonization in children attending child care centers," Journal of Clinical Microbiology, vol. 49, no. 3, pp. 10411047, 2011.

[5] C. Nsofor, V. Nwokenkwo, and C. Nwaokpa, "Nasal Carriage of Staphylococcus Aureus among Apparently Healthy School Children in Owerri Metropolis, Nigeria," MOJ Cell Science \& Report, vol. 2, no. 5, 2015.

[6] D. Campoccia, L. Montanaro, and C. R. Arciola, "The significance of infection related to orthopedic devices and issues of antibiotic resistance," Biomaterials, vol. 27, no. 11, pp. 2331-2339, 2006.

[7] J. K. Rudkin, M. Laabei, A. M. Edwards et al., "Oxacillin alters the toxin expression profile of community-associated methicillin-resistant Staphylococcus aureus," Antimicrobial Agents and Chemotherapy, vol. 58, no. 2, pp. 1100-1107, 2014.

[8] M. S. Assafi, R. Q. Mohammed, and N. R. Hussein, "Nasal carriage rates of Staphylococcus aureus and Community associatedmethicillin resistant Staphylococcus aureus among university students," Journal of Microbiology Research, vol. 5, no. 4, pp. 123127, 2015.

[9] F. Davoodabadi, S. Mobasherizadeh, K. Mostafavizadeh et al., "Nasal colonization in children with community acquired methicillin-resistant Staphylococcus aureus," Advanced Biomedical Research, vol. 5, no. 1, p. 86, 2016.

[10] S. Ansari, R. Gautam, S. Shrestha, S. R. Ansari, S. N. Subedi, and M. R. Chhetri, "Risk factors assessment for nasal colonization of Staphylococcus aureus and its methicillin resistant strains among pre-clinical medical students of Nepal," BMC Research Notes, vol. 9, no. 1, 2016.

[11] J. L. Raygada and D. P. Levine, "Managing CA-MRSA infections: Current and emerging options," Infections in Medicine, vol. 26, no. 2, pp. 49-58, 2009.

[12] A. Srinivasan, S. E. Seifried, L. Zhu et al., "Increasing prevalence of nasal and rectal colonization with methicillin-resistant Staphylococcus aureus in children with cancer," Pediatric Blood \& Cancer, vol. 55, no. 7, pp. 1317-1322, 2010.

[13] C. L. Maree, S. J. Eells, J. Tan et al., "Risk factors for infection and colonization with community-associated methicillin-resistant Staphylococcus aureus in the Los Angeles County jail: A casecontrol study," Clinical Infectious Diseases, vol. 51, no. 11, pp. 1248-1257, 2010.

[14] N. Sobhy, F. Aly, O. A. El Kader, A. Ghazal, and A. Elbaradei, "Community-acquired methicillin-resistant Staphylococcus aureus from skin and soft tissue infections (in a sample of Egyptian population): Analysis of mec gene and staphylococcal cassette chromosome," The Brazilian Journal of Infectious Diseases, vol. 16, no. 5, pp. 426-431, 2012.

[15] CLSI, Performance standards for antimicrobial susceptibility testing, P. A. Wayne, Ed., Suppl. M100, Clinical and Laboratory Standards Institute, 27th edition, 2017.

[16] D. Eibach, M. Nagel, B. Hogan et al., "Nasal carriage of staphylococcus aureus among children in the Ashanti region of Ghana," PLoS ONE, vol. 12, no. 1, 2017.

[17] M. Dinić, S. Vuković, B. Kocić, D. S. Dordević, and M. Bogdanović, "Nasal carriage of Staphylococcus aureus in healthy adults and in school children," Acta Facultatis Medicae Naissensis, vol. 30, no. 1, pp. 31-36, 2013.

[18] N. R. Hussein, Z. Basharat, A. H. Muhammed, and S. A. AlDabbagh, "Comparative evaluation of MRSA nasal colonization 
epidemiology in the Urban and Rural Secondary School Community of Kurdistan, Iraq," PLoS ONE, vol. 10, no. 5, 2015.

[19] M. Okwu, S. Bamgbala, and W. Aborisade, "Prevalence of nasal carriage of community-associated Methicillin-resistant Staphylococcus aureus (CA-MRSA) among healthy primary school children in Okada, Nigeria," Prevalence, vol. 2, no. 4, pp. 22243186, 2012.

[20] S. Esposito, L. Terranova, A. Zampiero et al., "Oropharyngeal and nasal carriage by healthy children," BMC Infectious Diseases, vol. 14, no. 1, 2014.

[21] V. Shetty, K. Trumbull, A. Hegde et al., "Prevalence of community-acquired methicillin-resistant staphylococcus aureus nasal colonization among children," Journal of Clinical and Diagnostic Research, vol. 8, no. 12, pp. DC12-DC15, 2014.

[22] S. Mobasherizadeh, H. Shojaei, S. Havaei et al., "Nasal carriage screening of community-associated methicillin resistant Staphylococcus aureus in healthy children of a developing country," Advanced Biomedical Research, vol. 5, no. 1, p. 144, 2016.

[23] M. Assafi, R. Polse, N. Hussein, A. Haji, and A. Issa, "The Prevalence of S. Aureus Nasal Colonisation and its Antibiotic Sensitivity Pattern amongst Primary School Pupils," Science Journal of University of Zakho, vol. 5, no. 1, pp. 7-10, 2017.

[24] T. Kejela and K. Bacha, "Prevalence and antibiotic susceptibility pattern of methicillin-resistant Staphylococcus aureus (MRSA) among primary school children and prisoners in Jimma Town, Southwest Ethiopia," Annals of Clinical Microbiology and Antimicrobials, vol. 12, no. 1, article no. 11, 2013.

[25] A. Reta, L. Gedefaw, T. Sewunet, and G. Beyene, "Nasal carriage, risk factors and antimicrobial susceptibility pattern of methicillin resistant Staphylococcus aureus among school children in Ethiopia," Journal of Medical Microbiology \& Diagnosis, vol. 4, no. 1, 2015.

[26] Organization WH, Antimicrobial resistance: global report on surveillance, World Health Organization, 2014.

[27] H. M. Alzoubi, A. A. Aqel, S. A. Al-Sarayreh, and E. AlZayadneh, "Methicillin-resistant Staphylococcus aureus nasal carriage among primary school-aged children from Jordan: Prevalence, antibiotic resistance and molecular characteristics," Journal of the Egyptian Public Health Association, vol. 89, no. 3, pp. 114-118, 2014.

[28] K. Van Nguyen, T. Zhang, B. N. T. Vu et al., "Staphylococcus aureus nasopharyngeal carriage in rural and urban northern Vietnam," Transactions of the Royal Society of Tropical Medicine and Hygiene, vol. 108, no. 12, pp. 783-790, 2014. 


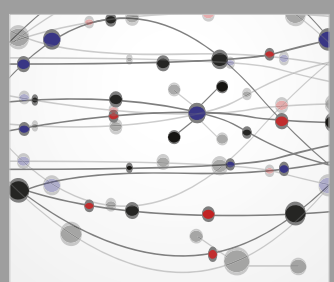

The Scientific World Journal
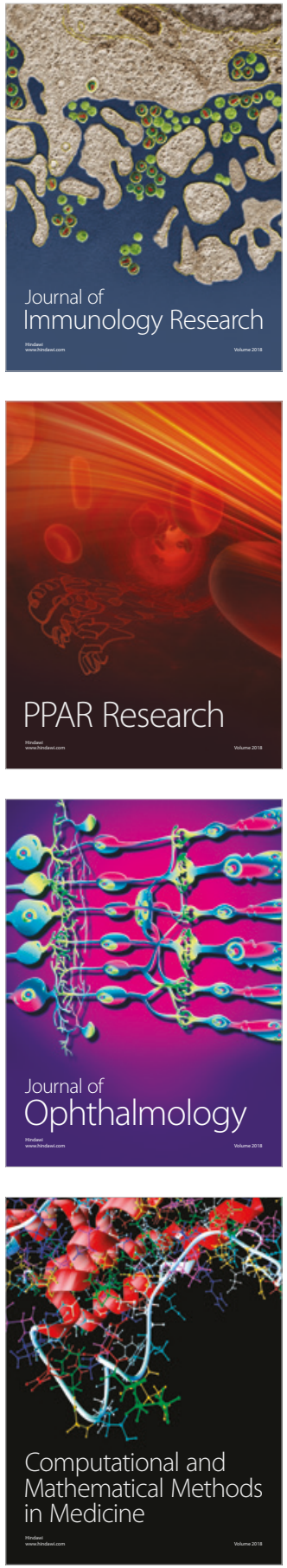

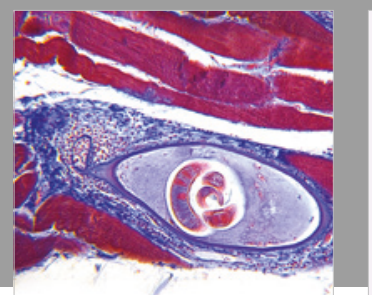

Gastroenterology Research and Practice

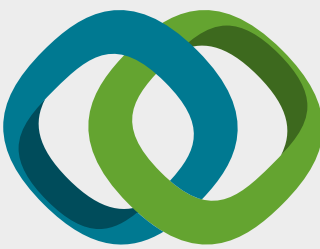

\section{Hindawi}

Submit your manuscripts at

www.hindawi.com
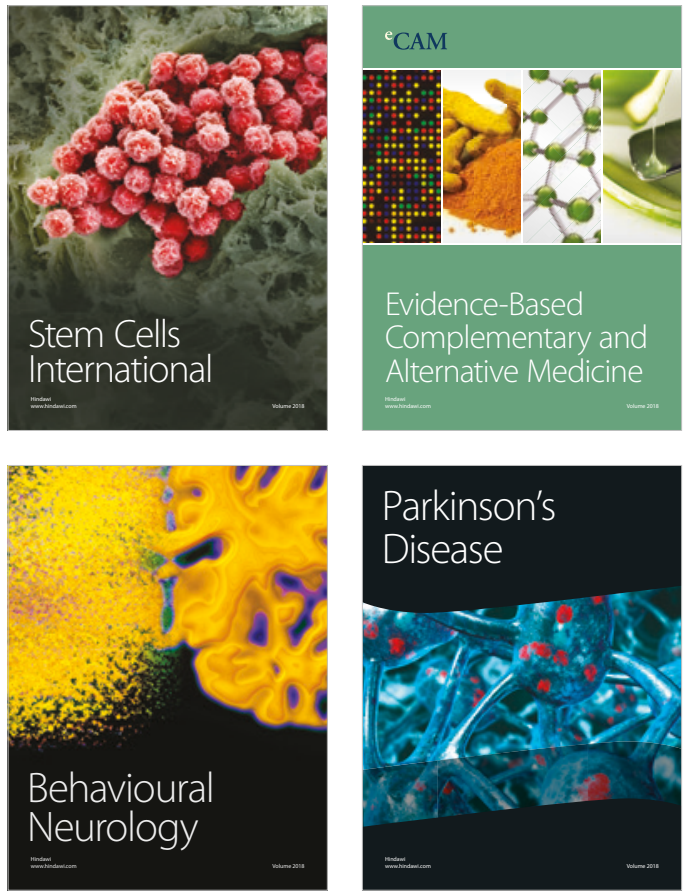

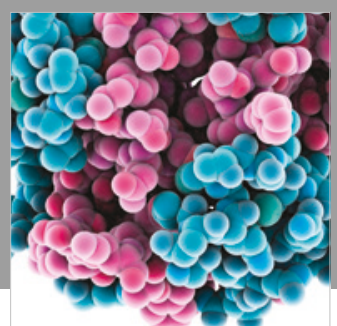

ournal of

Diabetes Research

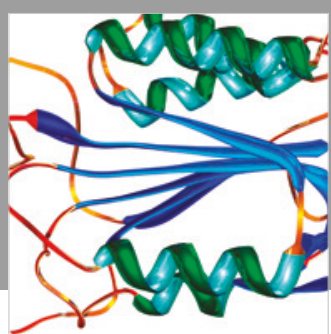

Disease Markers
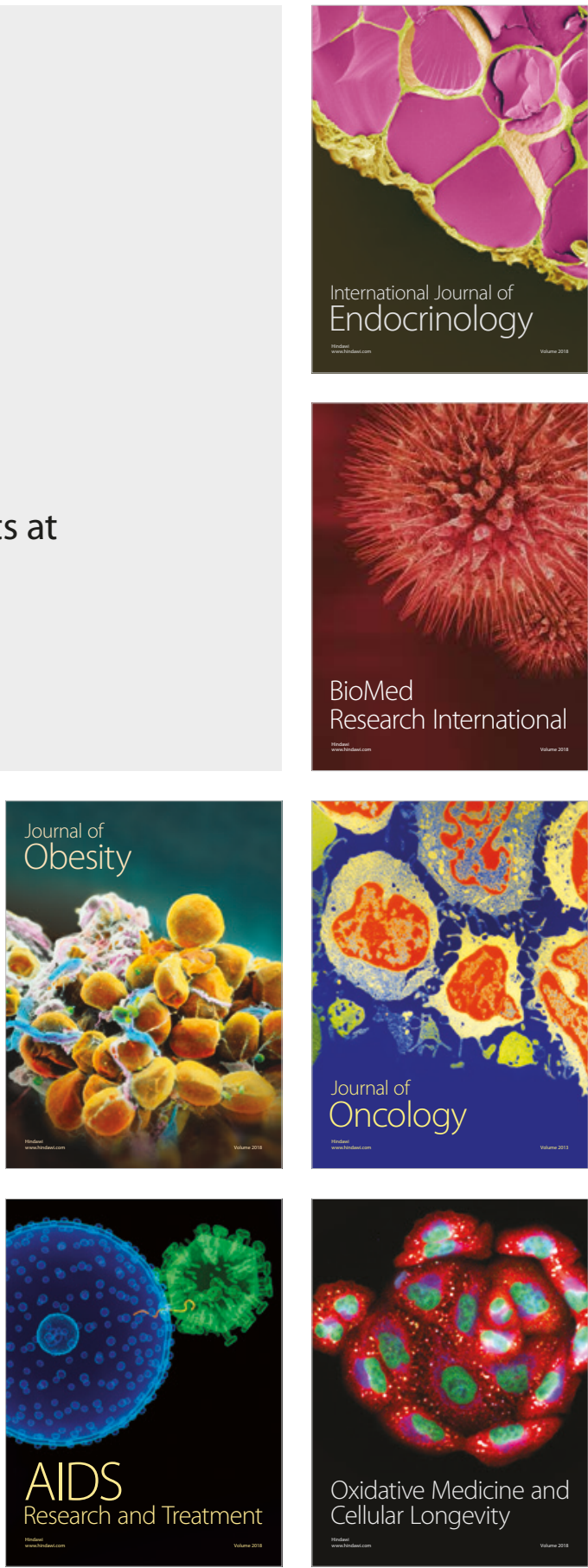